\title{
Intravenous Lipid Emulsion for Local Anesthetic Toxicity: A Review of the Literature
}

\author{
Kristen L. Felice, PharmD, Heather M. Schumann, PharmD
}

University of Illinois at Chicago College of Pharmacy, Department of Pharmacy Practice, Chicago, Illinois

\begin{abstract}
Introduction: The use of intravenous lipid emulsion (IVLE) has been proposed as a new potential treatment for local anesthetic toxicity. Local anesthetics work through reversible binding at sodium channels, and signs and symptoms of toxicity include central nervous system and cardiovascular effects. Cardiovascular collapse is a potential result of local anesthetic toxicity, and is generally resistant to resuscitation efforts with standard measures.

Discussion: Various animal studies have been published investigating the use of IVLE in local anesthetic toxicity. IVLE has been shown to increase the lethal dose of bupivacaine required, resuscitate animals that underwent local anesthetic-induced cardiovascular collapse, and more quickly reduce the amount of local anesthetic in the myocardium (compared to administration of control solution). Four human case reports utilizing IVLE for presumed local anesthetic toxicity, with varying presentations, are reviewed.

Conclusions: IVLE has shown to be an interesting prospect for local anesthetic toxicity. Human case reports have shown successful resuscitation with use of IVLE, using varying dosing regimens. More studies are needed to determine the optimal dosing regimen, as well as to determine the potential adverse effects of IVLE when used in this setting.
\end{abstract}

\section{INTRODUCTION}

A new potential antidote for local anesthetic (LA) toxicity has been gaining increasing attention in the literature, although this has largely been limited to anesthesia literature. Intravenous lipid emulsion (IVLE) has been reported as rescue therapy for LA toxicity. Both animal studies and limited human case reports have described successful resuscitation with IVLE in the face of presumed or documented LA toxicity. This presents an interesting therapeutic option, particularly in the setting of cardiovascular collapse induced by LAs, which has largely been resistant to standard resuscitation efforts. The purpose of this article is to provide an overview of LAs, their toxicity, and the proposed management of clinical signs and symptoms of LA toxicity with the use of IVLE, utilizing a review of available animal studies and human case reports.

\section{LOCAL ANESTHETICS}

Local anesthetic agents are commonly used in various therapeutic modalities [1]. Local anesthesia involves the injection of LA into the skin and subcutaneous tissue, anesthetizing the skin surrounding the injection site. Topical anesthesia involves the application of LA to the skin or mucous membranes, decreasing sensation in the areas of application. Regional anesthesia consists of the injection of LA toward central or peripheral nerve targets, eliciting anesthesia in the regions of the body that are served by the targeted nerves.

Toxicity is related to the structure and mechanism of action of LAs. Local anesthetics have three basic components to their chemical structure: a hydrophilic amine end, a lipophilic aromatic end, and a linkage connecting the two [2]. This linkage can either be an ester, with procaine serving as the prototype, or an amide, with

Keywords: Lipid emulsion, local anesthetic, toxicity There was no outside funding of any kind used for this study.

Corresponding Author: Heather M. Schumann, Pharm D, Emergency Medicine Clinical Pharmacist, University of Illinois at Chicago College of Pharmacy, Department of Pharmacy Practice, 833 South Wood Street, M/C 886, Room 164, Chicago, Illinois 60612.Email: EyrichHM@uic.edu 
Table1: Properties of Individual Local Anesthetics

\begin{tabular}{|c|c|c|c|c|c|c|c|}
\hline $\begin{array}{l}\text { Local } \\
\text { Anesthetic }\end{array}$ & Structure & $\begin{array}{l}\text { Time to } \\
\text { Onset of } \\
\text { Action }\end{array}$ & $\begin{array}{l}\text { Duration } \\
\text { of Action }\end{array}$ & $\begin{array}{c}\text { Half-life } \\
\text { (hours) }\end{array}$ & $\begin{array}{l}\text { n-octanol/ } \\
\text { buffer } \\
\text { Partition } \\
\text { Coefficient }\end{array}$ & $\begin{array}{l}\text { Maximum } \\
\text { Dose (mg)* }\end{array}$ & $\begin{array}{l}\text { Maximum } \\
\text { Dose } \\
\text { (mg/kg)* }\end{array}$ \\
\hline Bupivacaine & Amide & Medium & Long & 2.7 & 346 & $150-175$ & $1-2.5$ \\
\hline Chloroprocaine & Ester & Short & Short & $<30 \mathrm{sec}$ & 9 & $800-1000$ & 10 \\
\hline Cocaine & Ester & Long & Long & $\mathrm{N} / \mathrm{A}$ & $\mathrm{n} / \mathrm{a}$ & 200 & $1.5-3$ \\
\hline Etidocaine & Amide & Short & Long & 2.6 & 800 & $200-300$ & $2-5$ \\
\hline Levobupivacaine & Amide & Medium & Long & $\mathrm{N} / \mathrm{A}$ & 346 & 150 & $2-2.5$ \\
\hline Lipocaine & Amide & Short & Medium & 1.6 & 43 & 300 & $4-5$ \\
\hline Mepivacaine & Amide & Short & Medium & 1.9 & 21 & $300-400$ & $4-5$ \\
\hline Prilocaine & Amide & Short & Medium & 1.5 & 25 & 500 & $5-7$ \\
\hline Procaine & Ester & Long & Short & $\mathrm{N} / \mathrm{A}$ & 1.7 & $\mathrm{n} / \mathrm{a}$ & 8 \\
\hline Ropivacaine & Amide & Medium & Long & 1.8 & 115 & 225 & $2.5-3$ \\
\hline Tetracaine & Ester & Long & Long & $\mathrm{N} / \mathrm{A}$ & 221 & 100 & 1.5 \\
\hline \multicolumn{8}{|c|}{$\begin{array}{l}\text { *Doses dependent on clinical situation; higher doses may be allowed with the co-administration of epinephrine. } \\
N / A, \text { not available } \\
{[2-5,7,8]}\end{array}$} \\
\hline
\end{tabular}

lidocaine representing the prototype. Ester-linked LAs are metabolized rapidly at the tissue or serum level by cholinesterases, while amide-linked LAs undergo slower metabolism in the liver [3,4]. Increasing the number of carbon atoms on either end of the molecule increases not only the lipophilicity of the agent, but also the duration of action and protein binding [2]. The LAs are weak bases with poor water solubility [3]. Therapeutically, LAs are thought to largely act through reversible binding at sodium channels [2]. They have the highest affinity for sodium channels that are in the open state, and it is estimated that $75 \%$ of sodium channels need to be inactivated to produce a clinical effect $[2,5]$. Local anesthetics can work at both ligand- and voltage-gated channels [6]. Local anesthetics may also have other metabolic effects, specifically acting on carnitine acylcarnitine translocase [6]. This enzyme helps to transfer fatty-acid components across the mitochondrial membrane so that oxidation may occur. Local anesthetics may prevent this translocation, preventing the complete oxidation of fatty acids and thereby leading to a depletion of adenosine triphosphate.

Individual LAs have differences in their pharmacokinetic profile, which also affects their toxicity [5]. The LAs that have been developed since 1955 are all amide-linked LAs, and include mepivacaine, prilocaine, bupivacaine, etidocaine, ropivacaine, and levobupivacaine [2]. The ester-linked LAs have low stability, leading to a poor shelf life [3]. Bupivacaine is the LA most commonly used in both obstetrics and surgery [5]. Bupivacaine enters quickly into the sodium channel but exits more slowly, with risk of resultant accumulation [5]. Levobupivacaine and ropivacaine have been shown to have decreased central nervous system (CNS) and cardiovascular toxicity than bupivacaine [5]. Ropivacaine is solely an
S-enantiomer and is structurally related to bupivacaine and mepivacaine [5]. Mepivacaine is an LA with intermediate duration of action and a safer toxicity profile than bupivacaine, and an LA of choice for patients at higher risk for cardiac adverse events [5]. More information regarding pharmacokinetic and pharmacodynamic differences in individual LAs is included in Table 1.

Reported rates of systemic toxicity from LA use have decreased over the past several decades $[1,9]$. Peripheral nerve blocks carry the highest rates of systemic toxicity, which is estimated to occur in 0.075 to $0.1 \%$ of procedures $[1,10]$. Systemic reactions from LA use are generally due to inadvertent intravascular administration of the agents, as opposed to a gross excess of LA use [1]. Changes in practice and increased attention to LA safety have been suggested since the 1980s, which may have helped lower rates of systemic toxicity [9]. These practices include administering LAs in divided doses, performing aspiration tests, following recommendations for dose limitations, and administering test doses (of epinephrine) to detect inadvertent intravascular administration [9]. In a 1995 survey of obstetric anesthesiologists, over 60\% of respondents indicated that they routinely administer an epinephrine-containing test dose to patients in labor [11]. Commonly recommended maximum doses of LAs are listed in Table $1[2-5,7,8]$. However, since most cases of LA toxicity result from inadvertent intravascular administration of LA instead of gross overdose of the medication, adherence to maximum recommended doses may not effectively eliminate cases of toxicity [1].

There are several general adverse effects of LAs, independent of toxicity. Allergic reactions are more common with ester LAs as compared to amides, and may range from minor dermatitis to 
anaphylaxis [1]. Neuropathy and transient neurological symptoms have been reported, in addition to idiosyncratic reactions $[1,2]$. Other adverse effects include myotoxicity and, occasionally, methemoglobinemia [2].

\section{LOCAL ANESTHETIC TOXICITY}

When considering the toxicity of LAs, it is important to consider first the systemic availability of the agent. The maximum concentration of LA in the serum is affected by multiple factors, including the speed of administration, site of administration, total amount of medication injected, and route of administration (intravenous [IV] vs. intra-arterial) [1]. The systemic absorption of LAs is directly affected by the vasculature of the injected area [2]. Various injection sites, listed by increasing rates of systemic absorption, include: spinal, sciatic/femoral, brachial plexus, epidural, caudal, intercostal, and interpleural [5]. Other factors influencing the extent of systemic absorption include the total dose of medication administered and the presence of epinephrine, which is sometimes co-administered with LAs [5]. Epinephrine works as a vasoconstrictor and helps lessen blood loss [2,5]. It may also be used to help detect intravascular administration of an LA, by allowing the health-care professional to monitor for increases in heart rate and blood pressure that may be due to intravascular administration of epinephrine and thus point to the possibility of intravascular LA administration [5]. Epinephrine, when administered in a dose of $5 \mu \mathrm{g} / \mathrm{mL}$ of LA $(1: 200,000)$ also reduces the amount of systemic absorption of the LA by approximately one third [5].

The serum concentration of an LA may correlate with clinical signs and symptoms of toxicity [1]. For example, lidocaine administration in regional blocks usually results in a serum concentration of 3-5 $\mu \mathrm{g} / \mathrm{mL}$ and therapeutic plasma concentrations of lidocaine are 1 to $5 \mu \mathrm{g} / \mathrm{mL}$ when used for ventricular arrhythmias $[1,12]$. Symptoms of toxicity may occur at concentrations $\geqslant 6 \mu \mathrm{g} / \mathrm{mL}$, convulsions may occur at concentrations $>10 \mu \mathrm{g} / \mathrm{mL}$, and cardiovascular collapse with levels $>30 \mu \mathrm{g} / \mathrm{mL}$ [1]. One confounder in the interpretation of serum concentrations of LAs is protein binding, which generally decreases with increasing drug concentrations [13]. In the clinical setting of probable LA toxicity, an elevated total drug concentration may be reflective of a high free drug concentration.

Signs and symptoms of systemic toxicity of LA may progress with time $[1,10]$. Early signs may be recognized as agitation, lightheadedness, altered mental status, visual changes, slurred speech, hypertension, and tachycardia [10]. Moderate toxicity may be exhibited as CNS excitation, cardiac arrhythmias, contractile depression, and conduction blockade [10]. Severe toxicity presents as hypotension, bradycardia, ventricular arrhythmias, and eventually cardiovascular collapse [10].

The CNS toxicity of LAs can begin as sedation at low drug concentrations, progress to CNS excitation, dizziness, paresthesias, anxiety, and fear of death, and result in uncontrolled muscular activity, tonic-clonic seizures, and CNS depression at higher concentrations [5]. Seizures that result from LA toxicity are generally self-limiting and precede signs of CNS and cardiovascular depression [2,5]. As such, seizures may alert health-care providers of the possibility of progression to CNS depression or impending cardiovascular collapse.

The cardiovascular toxicity of LAs is generally the most ominous presentation of toxicity. When present in excess, the actions of LAs on sodium channels contributes to cardiovascular toxicity, and may also be affected by secondary effects of LAs on calcium and potassium channels, and the inhibition of cyclic adenosine monophosphate production [5]. The most concerning aspect of LA-induced cardiovascular collapse is that it is generally very difficult to resuscitate patients who have asystole caused by bupivacaine [14]. Standard resuscitation efforts-i.e., advanced cardiac life support (ACLS) - may not be effective in resuscitating these patients [14]. The long-acting LAs, such as bupivacaine, are more strongly associated with cardiovascular toxicity compared to the short-acting agents [5]. Bupivacaine has been found to be especially cardiotoxic, with a strong attraction to the myocardial sodium channels, as well as slow dissociation from the sodium channels due to the drug's lipophilic properties [5]. Bupivacaine also has effects on L-type calcium channels, which may contribute to its cardiovascular toxicity [5]. Bupivacaine is a racemic compound, but it was discovered that in general S-enantiomers of LAs are associated with decreased toxicity, prolonged duration of action, and higher potency [2]. This leads to the production of levobupivacaine, which is the S-enantiomer of bupivacaine, and ropivacaine, which is formulated as a pure S-enantiomer [2,5].

\section{INTRAVENOUS LIPID EMULSION (IVLE) IN LOCAL ANESTHETIC TOXICITY}

One interesting discovery that shows promise for the resuscitation of patients suffering from LA-induced cardiovascular collapse is the use of IVLE. IVLE is indicated for use in patients receiving parenteral nutrition for a prolonged duration who require supplementation of essential fatty acids and calories, or for the prevention of essential fatty acid deficiency [15]. The commercial IVLE products are available in various concentrations. The $20 \%$ formulation of IVLE contains 20\% soybean oil, 1.2\% egg yolk phospholipids, $2.25 \%$ glycerin, and the remainder is water [15]. The osmolality of IVLE is approximately $350 \mathrm{mOsm} / \mathrm{kg}$ water and $260 \mathrm{mOsm} / \mathrm{kg}$ lipid emulsion [15]. The lipid particles of IVLE are cleared from the blood in a similar manner to chylomicrons, the endogenous particles from which they are modeled [15]. Important differences between the IVLE lipid particles and endogenous chylomicrons are that the IVLE lipid particles do not contain cholesterol and have supplementary phospholipid vesicles in addition to the phospholipid bilayer surrounding triacylglycerol particles [16]. The lipid particles gain apolipoprotein E and apolipoprotein Cs upon administration into the vasculature [16]. These proteins are largely obtained from high-density lipoprotein [16]. The triacylglycerol is then released from the lipid particles by lipoprotein lipase [16]. After lipolysis occurs, the 
remaining particles generally travel through the serum to hepatic tissue or may be internalized into endothelial cells [16].

There are multiple theories about the mechanism of action of IVLE in LA toxicity. One theory is that IVLE serves as a "lipid sink," providing a large lipid phase in the serum that is able to extract LAs from the plasma [17]. This may be true at the tissue level, as well [18]. Another theory is that IVLE has metabolic effects by inhibiting mitochondrial metabolism of lipids, reducing tissue acidosis and decreasing carbon dioxide production during times of myocardial ischemia [17]. Also, as LAs may impair fatty acid delivery to the mitochondria, IVLE may work to saturate this impaired fatty acid delivery to enable further energy production [17]. Additionally, fatty acids, as found in IVLE, have been shown to activate calcium and potassium channels, which have been associated with LA-induced cardiotoxicity $[19,20]$.

\section{ANIMAL STUDIES}

The utility of IVLE in LA toxicity was discovered serendipitously by a team of researchers performing animal studies. As bupivacaine is a commonly used LA with a significant concern of cardiovascular toxicity, it is not surprising that the majority of studies investigating the use of IVLE for LA toxicity utilize bupivacaine. In the first arm of one study, male rats received pretreatment with saline (control) or IVLE 10\%, 20\%, or 30\% [21]. Table 2 presents dosing details of medications used in animal studies $[17,18,21]$. After the pretreatment, bupivacaine $0.75 \%$ was administered until subjects had 10 seconds of asystole [21]. Blood samples were drawn to determine the lethal dose and concentration of bupivacaine. The median lethal dose of bupivacaine increased with increasing concentrations of IVLE pretreatment, $17.8 \mathrm{mg} / \mathrm{kg}$ in the control group, compared to $27.6 \mathrm{mg} / \mathrm{kg}, 49.8 \mathrm{mg} / \mathrm{kg}$, and $82 \mathrm{mg} / \mathrm{kg}$ in the IVLE $10 \%, 20 \%$, and $30 \%$ groups, respectively ( $p<0.001$ between all groups). The mean plasma bupivacaine concentrations at the time of asystole was also statistically significantly different between the control and IVLE 30\% groups, $93.3 \pm 7.6 \mu \mathrm{g} / \mathrm{mL}$ and $212 \pm 45 \mu \mathrm{g} / \mathrm{mL}$, respectively $(p<0.001)$. The second arm of the study involved bupivacaine administered in various doses, followed by either saline or IVLE 30\% bolus, and then a continuous infusion. The $\mathrm{LD}_{50}$ of bupivacaine with saline resuscitation was $12.5 \mathrm{mg} / \mathrm{kg}$ (95\% confidence interval $11.8-13.4 \mathrm{mg} / \mathrm{kg}$ ) versus $18.5 \mathrm{mg} / \mathrm{kg}$ (95\% confidence interval $17.8-19.3 \mathrm{mg} / \mathrm{kg}$ ) in the IVLE group. This study showed that pretreatment with IVLE increases the median lethal dose and mean lethal concentration of bupivacaine, and resuscitation with IVLE increases the $\mathrm{LD}_{50}$ of bupivacaine as well.

Another animal study evaluated the utility of IVLE following LA-induced cardiovascular collapse. Twelve male hounds received a weight-based dose of bupivacaine to induce circulatory arrest, defined as mean blood pressure $<30 \mathrm{mmHg}$ and heart

\begin{tabular}{|c|c|c|c|c|}
\hline & $\begin{array}{l}\text { 1st Medication } \\
\text { Administered }\end{array}$ & $\begin{array}{l}\text { 1st Medication } \\
\text { Dose }\end{array}$ & $\begin{array}{l}\text { 2nd Medication } \\
\text { Administered }\end{array}$ & $\begin{array}{l}\text { 2nd Medication } \\
\text { Dose }\end{array}$ \\
\hline $\begin{array}{l}\text { Weinberg et al, } 1998 \\
\text { Arm } 1 \text { [21] }\end{array}$ & $\begin{array}{l}\text { Saline (control) } \\
\text { IVLE } 10 \% \\
\text { IVLE } 20 \% \\
\text { IVLE } 30 \%\end{array}$ & $\begin{array}{l}3 \mathrm{~mL} / \mathrm{kg} / \text { minute } \\
\text { for } 5 \text { minutes }\end{array}$ & Bupivacaine $0.75 \%$ & $10 \mathrm{mg} / \mathrm{kg} / \mathrm{minute}$ \\
\hline $\begin{array}{l}\text { Weinberg et al, } 1998 \\
\text { Arm } 2 \text { [21] }\end{array}$ & $\begin{array}{l}\text { Bupivacaine } \\
0.75 \%\end{array}$ & $\begin{array}{l}\text { Various doses over } \\
10 \text { seconds }\end{array}$ & $\begin{array}{l}\text { Saline (control) } \\
\text { IVLE } 30 \%\end{array}$ & $\begin{array}{l}7.5 \mathrm{~mL} / \mathrm{kg} \text { over } 30 \\
\text { seconds, then } \\
3 \mathrm{~mL} / \mathrm{kg} / \mathrm{min} \text { for } \\
2 \text { minutes }\end{array}$ \\
\hline Weinberg et al, 2003 [18] & Bupivacaine & $\begin{array}{l}10 \mathrm{mg} / \mathrm{kg} \text { over } \\
10 \text { seconds }\end{array}$ & $\begin{array}{l}\text { Saline (control) } \\
\text { IVLE } 20 \%\end{array}$ & $\begin{array}{l}4 \mathrm{~mL} / \mathrm{kg} \text { over } 2 \\
\text { minutes, then } \\
0.5 \mathrm{~mL} / \mathrm{kg} / \mathrm{min} \text { for } \\
10 \text { minutes }\end{array}$ \\
\hline $\begin{array}{l}\text { Weinberg et al, } 2006 \\
\text { Arm } 1 \text { [17] }\end{array}$ & $\begin{array}{l}\text { Bupivacaine } \\
10 \mathrm{mmol} / \mathrm{L}\end{array}$ & $\begin{array}{l}\text { Administered for } \\
30 \text { seconds to } \\
\text { concentration of } \\
500 \mu \mathrm{mol} / \mathrm{L}\end{array}$ & $\begin{array}{l}\text { Buffer (control) } \\
\text { IVLE } 20 \%\end{array}$ & $\begin{array}{l}\text { Infused to } \\
\text { triglyceride } \\
\text { concentration 1\% }\end{array}$ \\
\hline $\begin{array}{l}\text { Weinberg et al, } 2006 \\
\text { Arm } 2 \text { [17] }\end{array}$ & $\begin{array}{l}\text { Bupivacaine } \\
10 \mathrm{mmol} / \mathrm{L} \\
\text { (radio-labeled) }\end{array}$ & $\begin{array}{l}\text { Administered for } \\
30 \text { seconds to } \\
\text { concentration of } \\
500 \mu \mathrm{mol} / \mathrm{L}\end{array}$ & $\begin{array}{l}\text { Buffer (control) } \\
\text { IVLE } 20 \%\end{array}$ & $\begin{array}{l}\text { Infused for } \\
2 \text { minutes } \\
\text { to triglyceride } \\
\text { concentration } 1 \%\end{array}$ \\
\hline $\begin{array}{l}\text { Weinberg et al, } 2006 \\
\text { Arm } 3 \text { [17] }\end{array}$ & $\begin{array}{l}\text { Bupivacaine } \\
10 \mathrm{mmol} / \mathrm{L} \\
\text { (radio-labeled) }\end{array}$ & $\begin{array}{l}\text { Administered for } \\
30 \text { seconds to } \\
\text { concentration of } \\
500 \mu \mathrm{mol} / \mathrm{L}\end{array}$ & $\begin{array}{l}\text { Buffer (control) } \\
\text { IVLE } 20 \%\end{array}$ & $\begin{array}{l}\text { Infused to } \\
\text { triglyceride } \\
\text { concentration 1\% }\end{array}$ \\
\hline
\end{tabular}


rate $<10$ beats per minute [18]. After a 10-minute period of internal cardiac massage, subjects received a bolus of either saline or IVLE $20 \%$ followed by a continuous infusion for 10 minutes.Of the subjects who received saline, none had return to normal sinus rhythm or a mean blood pressure $>20 \mathrm{~mm} \mathrm{Hg}$. Among the subjects who received IVLE, all had return to normal sinus rhythm within 5 minutes of IVLE administration, return to mean blood pressure $>30 \mathrm{~mm} \mathrm{Hg}$ within 10 minutes, and near-baseline heart rate and blood pressure with normal electrocardiographs (EKGs) within 30 minutes of IVLE administration. The administration of IVLE was shown to be effective in resuscitation of bupivacaineinduced cardiovascular collapse.

One final animal study was performed in isolated rat hearts into which bupivacaine was infused to a final concentration of $500 \mu \mathrm{mol} / \mathrm{L}$ in the heart to induce asystole [17]. Subsequently, IVLE 20\% was infused to a final triglyceride concentration of $1 \%$ or buffer solution was infused for the control group. When the IVLE or buffer (control) solution was infused immediately at the end of the bupivacaine infusion, the hearts that received IVLE had approximately a 30\% reduction in the time to the first heart beat compared to control ( $44.6 \pm 3.5$ seconds vs. $63.8 \pm 4.3$ seconds, respectively, $p<0.01$ ). The IVLE hearts also had a faster return to $90 \%$ of their baseline rate pressure product versus control hearts, at $124.7 \pm 12.4$ seconds and $219.8 \pm 25.6$ seconds, respectively $(p<0.01)$. In a second study arm, the protocol was modified and the infused bupivacaine solution was radiolabeled. The investigators extracted myocardial tissue samples from the left ventricular apex immediately before the bupivacaine infusion, at the end of the bupivacaine infusion, then every 30 seconds to 2 minutes thereafter. The decay curve time constants for the percent decrease in bupivacaine content versus time graph were 83 seconds for the control group and 37 seconds for the IVLE group $(p<0.002)$. Additionally, in a third arm of the study, radiolabeled bupivacaine was utilized, and the IVLE infusion was started 75 seconds after the end of the bupivacaine infusion. The use of IVLE infusion increased the radioactive counts in the circulating solution as compared to the control infusion, although the only time point with a difference in the groups was at 15 seconds after the start of the IVLE infusion $(183 \pm 24 \mathrm{nmol} / 15$ seconds for IVLE vs. $121 \pm 17 \mathrm{nmol} / 15$ seconds for control, $p=0.0084$ ). This suggests that less of the radiolabeled bupivacaine infused was in the myocardial tissues initially after IVLE administration.

\section{HUMAN CASE REPORTS}

Despite the inherent flaws and limitations of animal studies in their applicability to human cases, there only are a handful of human case reports in the literature describing the successful use of IVLE in resuscitation efforts involving suspected or documented LA toxicity. The first case involved a 58-year-old male who developed seizures and asystolic cardiac arrest after receiving regional anesthesia with $40 \mathrm{~mL}$ solution containing $20 \mathrm{~mL}$ mepivacine $1.5 \%$ and $20 \mathrm{~mL}$ bupivacaine $0.5 \%$ [22]. See Tables 3 and 4 for further details regarding medications administered in human case reports [22-25]. Advanced cardiac life support was initiated without clinical response, which included administration of propofol [22]. Subsequently, IVLE 20\% $100 \mathrm{~mL}$ was administered in conjunction with ongoing resuscitation efforts, with return of spontaneous circulation. The IVLE 20\% was then administered at $0.5 \mathrm{~mL} / \mathrm{kg} / \mathrm{min}$ for 2 hours. The patient recovered without resultant neurologic deficits or signs or symptoms of adverse effects of IVLE use when followed for 2 weeks. Due to elevated cardiac enzymes, the patient underwent cardiac catheterization, which showed total occlusion of his right coronary artery and a reduced left ventricular ejection fraction. The authors postulated that the patient's preexisting conduction abnormalities
Table 3: Summary of Medications Used in Human Case Reports

\begin{tabular}{|c|c|c|c|}
\hline $\begin{array}{l}\text { Subject } \\
\text { Demographics }\end{array}$ & Local Anesthetic & $\begin{array}{c}\text { Site of } \\
\text { Administration }\end{array}$ & $\begin{array}{c}\text { Pre-IVLE } \\
\text { Resuscitation } \\
\text { Medications }\end{array}$ \\
\hline 58-year-old male [22] & $\begin{array}{l}\text { Mepivacaine } 1.5 \%, 20 \mathrm{~mL} \\
\text { Bupivacaine } 0.5 \%, 20 \mathrm{~mL}\end{array}$ & Brachial plexus & $\begin{array}{l}\text { Propofol } \\
\text { Epinephrine } \\
\text { Atropine } \\
\text { Amiodarone } \\
\text { Vasopressin } \\
\text { Monophasic } \\
\text { defibrillation }\end{array}$ \\
\hline 84-year-old female [23] & Ropivacaine 1\%, $40 \mathrm{~mL}$ & Brachial plexus & $\begin{array}{l}\text { Thiopental } \\
\text { Epinephrine }\end{array}$ \\
\hline 75-year-old female [24] & Levobupivacaine $0.5 \%, 20 \mathrm{~mL}$ & Lumbar plexus & $\begin{array}{l}\text { Metaraminol } \\
\text { Propofol } \\
\text { Succinylcholine }\end{array}$ \\
\hline 18-year-old female [25] & $\begin{array}{l}\text { Isobaric bupivacaine } 0.25 \%, 6 \mathrm{~mL} \\
\text { Bupivacaine } 0.5 \%, 10 \mathrm{~mL}\end{array}$ & Epidural, L1-L2 & None \\
\hline
\end{tabular}


Table 4: IVLE Use in Human Case Reports

\begin{tabular}{|c|c|c|c|c|c|}
\hline & $\begin{array}{l}\text { IVLE } 20 \% \\
\text { Bolus Dose }\end{array}$ & $\begin{array}{c}\text { IVLE } \mathbf{2 0 \%} \\
\text { Bolus } \\
\text { (mL/kg) }\end{array}$ & $\begin{array}{c}\text { IVLE } \mathbf{2 0 \%} \\
\text { Infusion Rate }\end{array}$ & $\begin{array}{l}\text { IVLE } \mathbf{2 0 \%} \\
\text { Infusion } \\
\text { (mL/kg) }\end{array}$ & $\begin{array}{c}\text { Total Dose } \\
\text { IVLE 20\% } \\
\text { (mL/kg) }\end{array}$ \\
\hline $\begin{array}{l}\text { 58-year-old } \\
\text { male [22] }\end{array}$ & $100 \mathrm{~mL}$ & 1.2 & $\begin{array}{l}0.5 \mathrm{~mL} / \mathrm{kg} / \mathrm{minute} \\
\text { for } 2 \text { hours }\end{array}$ & 60 & 61.2 \\
\hline $\begin{array}{l}\text { 84-year-old } \\
\text { female [23] }\end{array}$ & $100 \mathrm{~mL}$ & 2 & $0.2 \mathrm{~mL} / \mathrm{kg} / \mathrm{min}$ & $\begin{array}{l}\text { Not } \\
\text { reported }\end{array}$ & $\begin{array}{c}\text { Effects seen } \\
\text { after total } \\
4 \mathrm{~mL} / \mathrm{kg}\end{array}$ \\
\hline $\begin{array}{l}\text { 75-year-old } \\
\text { female [24] }\end{array}$ & $100 \mathrm{~mL}$ & 1.2 & None & None & 1.2 \\
\hline $\begin{array}{l}\text { 18-year-old } \\
\text { female [25] }\end{array}$ & $\begin{array}{c}100 \mathrm{~mL} \\
\text { (administered } \\
\text { in } 2 \text { divided } \\
\text { doses) }\end{array}$ & $\begin{array}{c}1.2 \\
\text { (administered } \\
\text { in } 2 \text { divided } \\
\text { doses) }\end{array}$ & $\begin{array}{l}400 \text { mL infused } \\
\text { "freely" }\end{array}$ & 4.7 & 5.8 \\
\hline
\end{tabular}

may have made him more susceptible to LA toxicity. Prior to IVLE infusion, the patient received propofol, which does contain $10 \%$ lipid, but was not effective in reversing the signs and symptoms of LA toxicity.

A second case report describes an 84-year-old female who presented for a brachial plexus block to facilitate repair of a Dupuytren contracture [23]. The patient inadvertently received $40 \mathrm{~mL}$ of ropivacaine $1 \%$ instead of ropivacaine $0.5 \%$ and developed a generalized tonic-clonic seizure, followed by asystolic cardiac arrest. After 10 minutes of resuscitation efforts, a 100-mL bolus of IVLE $20 \%$ was administered, followed by a continuous infusion at $10 \mathrm{~mL} / \mathrm{min}(0.2 \mathrm{~mL} / \mathrm{kg} / \mathrm{min})$. Once $4 \mathrm{~mL} / \mathrm{kg}$ had been administered in total, the patient developed wide complex tachycardia. She subsequently regained a pulse and her systolic blood pressure was $100 \mathrm{mmHg}$. A pacemaker wire was later inserted and the patient was extubated after 3 hours. She made a complete recovery with discharge to home in 4 days. This patient's advanced age and preexisting conduction abnormalities may have put her at higher risk for adverse effects of the LA use and procedure.

An interesting case report describes the use of IVLE prior to complete cardiovascular collapse in a 75-year-old female who presented for repair of a fractured femur neck [24]. The patient underwent a lumbar plexus block using levobupivacaine $0.5 \%$ injected to a total of $20 \mathrm{~mL}$, and subsequently experienced a convulsion with EKG changes. In addition to other resuscitation measures, a 100-mL bolus of IVLE $20 \%$ was administered over 5 minutes. The patient's blood pressure improved during the infusion, and 10 minutes after the IVLE administration, the patient's vital signs and EKG were within normal limits. The decision was made to proceed with the surgery using volatile anesthesia, which the patient tolerated well without any further complications. This case describes stabilization of a patient with presumed local anesthetic toxicity prior to full cardiovascular collapse, suggesting that IVLE may have a role in the early management of suspected LA toxicity.
One final case report was recently published involving a pregnant 18-year-old female who received IVLE for CNS signs and symptoms that were possibly indicative of LA toxicity [25]. She presented at 38 weeks gestational age for induction of labor, with fetal decelerations noted. An epidural was performed at L1-L2, then the patient received a $4-\mathrm{mL}$ test dose of lidocaine $2 \%$, subsequently receiving $6 \mathrm{~mL}$ of isobaric bupivacaine $0.25 \%$ over $2-3$ minutes. She later received $100 \mu \mathrm{g}$ of fentanyl and $10 \mathrm{~mL}$ of bupivacaine $0.5 \%$ through the epidural catheter. The patient decompensated and became unresponsive, with twitching of her extremities and face noted. The patient received 2 boluses of $50 \mathrm{~mL}$ IVLE 20\%; the remaining $400 \mathrm{~mL}$ of solution in the bag was infused "freely." The patient had return to consciousness within 30 seconds of the IVLE administration, and a cesarean section was performed emergently under general anesthesia. The neonate was intubated but later extubated in the operating room. Both mother and neonate were discharged to home on postoperative day 4 . This case report describes the use of IVLE in a pregnant woman with presumed LA toxicity following suspected inadvertent intravascular administration of LA. It is interesting that the use of IVLE in this case was guided mainly by CNS, rather than cardiovascular, effects of the presumed toxicity.

\section{IVLE DOSING}

IVLE as rescue therapy following LA toxicity is an off-label use of this treatment, without specific dosing regimens approved for this use. Formal dose-ranging studies have not been performed in humans, and dosing information can only be extrapolated from animal studies and human case reports. While the human case reports all used IVLE 20\%, the amount infused varied with each case [22-25]. The various dosing regimens in the case reports described are summarized in Table 4 [22-25].

Although caution must be taken when assessing information on a website held by a private entity, Weinberg and colleagues have developed a website that may serve as a reference site for 
this topic, at www.lipidrescue.org [26]. Here, the authors propose a dosing regimen of IVLE $20 \%$ as a bolus of $1.5 \mathrm{~mL} / \mathrm{kg}$ over 1 minute, followed by a continuous infusion of $0.25 \mathrm{~mL} / \mathrm{kg} / \mathrm{min}$ for 30 to 60 minutes. In the setting of hypotension, the infusion may be increased to $0.5 \mathrm{~mL} / \mathrm{kg} / \mathrm{min}$. The authors suggest that the patient may be re-bolused 1 or 2 times every 3-5 minutes, with a recommended overall total dose of $8 \mathrm{~mL} / \mathrm{kg}$. It is to be noted that IVLE should be used in patients who do not respond to standard resuscitation efforts, and that chest compressions still need to be performed to allow circulation of the IVLE throughout the body.

Clearly, there are discrepancies between what has been suggested by researchers and what is actually being done in the limited experience with case reports. While a dose-ranging study in humans would be ideal, this is unethical given the clinical situation. Thus, the ideal dose and dosing regimen of IVLE in LA toxicity remains to be determined.

\section{CONCERNS OF IVLE USE}

As with any FDA-labeled medication, the individual IVLE products carry with them a set of contraindications to use and adverse effects. However, the extent to which these apply in the setting of LA-induced cardiovascular collapse or resuscitation, for which IVLE is not FDA-approved, remains to be defined. The general contraindication to IVLE use is the presence of disorders of fat metabolism. Other contraindications not published in the product's package insert include egg allergy and acute myocardial infarction $[15,27]$. The use of IVLE is cautioned in patients with anemia, severe liver disease, coagulopathies, pulmonary disease, and in patients at risk for fat embolism [15]. The most common adverse effects from general IVLE use are those related to contamination of the administration site and irritation of the veins likely due to other solutions co-infused with IVLE [15]. Early or immediate adverse effects of IVLE include allergic reactions, headache, somnolence, dizziness, diaphoresis, dyspnea, nausea/vomiting, hyperthermia, and hypercoagulability [15]. More delayed adverse effects of IVLE include thrombocytopenia, jaundice, overloading syndrome, increased liver function tests, leucopenia, hepatomegaly, and splenomegaly; pancreatitis has rarely been associated with IVLE use $[15,28]$. Those adverse effects that may be dose- or rate-related include pulmonary embolus or fat embolus, and pulmonary vasoconstriction may result from bolus administration of IVLE [6,27]. There were no adverse effects reported with IVLE use in the four human case reports mentioned above, although further investigation is warranted.

\section{PROPOFOL-AN ACCEPTABLE SUBSTITUTE?}

Propofol is formulated in a $10 \%$ lipid emulsion vehicle, thus also being a potential lipid emulsion source during resuscitation efforts. Both propofol and IVLE are formulated with an average fat particle size between 100 and $300 \mathrm{~nm}$ [29]. However, there have been several valid concerns raised regarding the use of propofol in this setting. If propofol were dosed in order to have anticonvulsant properties, the patient would not receive enough lipid component for IVLE use in LA toxicity [10]. Additionally, a large volume of emulsion would need to be delivered if propofol was used for therapeutic IVLE use, as it only contains IVLE 10\%, compared to the $20 \%$ commonly used in the case reports [30]. Propofol was administered in two of the presented human case reports, without any reported cessation of signs and symptoms of presumed LA toxicity $[22,24]$. Likewise, if the propofol was dosed based on the lipid component, this would result in a gross overdose of propofol. Propofol use carries with it other risks in the setting of cardiovascular collapse, including hypotension and mitochondrial damage [13]. Propofol may also be more detrimental to the patient in this setting, as it is a negative chronotrope, inotrope, and dromotrope [31]. Adverse effects reported with propofol include second-degree AV block, bradycardia, and asystole [31]. Propofol carries with it many risks and concerns compared to IVLE alone, thus should not be considered a substitute for IVLE for LA-induced cardiovascular collapse [30].

\section{CONCLUSION}

The use of IVLE in LA toxicity is gaining attention and discussion. Four unique human case reports have described successful use of IVLE in presumed LA toxicity both in the setting of, and possibly preceding, cardiovascular collapse. It is encouraging that this therapeutic option is available, as resuscitative efforts following bupivacaine-induced cardiac arrest have largely been resistant to standard measures. The animal studies investigating IVLE use for LA toxicity all utilized bupivacaine as the LA, which is likely due to its high level of cardiotoxicity and common use in procedures $[17,18,21]$. However, the human case reports discussed involved not only bupivacaine, but also showed the successful use of IVLE in cases of presumed LA toxicity involving mepivacaine, ropivacaine, and levobupivacaine [22-24]. As bupivacaine is associated with significant cardiovascular toxicity, the use of IVLE could possibly be applied to other LAs, should significant toxicity occur. It is still recommended that standard resuscitation efforts, such as ACLS, be utilized before using IVLE [26]. Although a dosing regimen has been proposed in the literature, formal dose-ranging studies are still lacking, and case reports have utilized other dosing regimens $[22-24,26]$.

There have also been studies and reports of IVLE being used in other toxicological settings, such as verapamil, clomipramine, propranolol, and bupropion/lamotrigine overdoses [27,32]. It has also been proposed that IVLE resuscitation could be used in the setting of cardiac surgeries, with bupivacaine used to induce cardiovascular collapse prior to the procedure, then using IVLE to effectively reverse these effects at the end of the procedure [14]. More research is warranted to validate these effects before IVLE resuscitation is performed electively, but it does present an interesting possible application. If IVLE proves to be successful in creating a "lipid sink" capable of extracting other lipophilic or amphiphilic 
agents in the case of overdose, this may prove to be a very useful agent for a number of toxicological emergencies [10].

The authors have no potential financial conflicts of interest to report

\section{REFERENCES}

1. Faccenda KA, Finucane BT. Complications of regional anaesthesia: incidence and prevention. Drug Safety 2001; 24(6):413-442.

2. Heavner JE. Local anesthetics. Curr Opin Anaesthesiol 2007;20:336-342.

3. Jackson T, McLure HA. Pharmacology of local anesthetics. Ophthalmol Clin North Am 2006;19:155-161.

4. Schwartz DR, Kaufman B. Local anesthetics. In: Flomenbaum NE, Goldfrank LR, Hoffman RS, Howland, MA, Lewin NA, Nelson LS, editors. Goldfrank's Toxicologic Emergencies. 8th ed. New York: McGraw-Hill: 2006. pp. 1004-1015.

5. Cox B, Durieux ME, Marcus MAE. Toxicity of local anaesthetics. Best Pract Res Clin Anaesthesiol 2003;17(1):111-136.

6. Picard J, Meek T. Lipid emulsion to treat overdose of local anaesthetic: the gift of the glob. Anaesthesia 2006;61:107-109.

7. Strichartz GR, Berde CB. Local anesthetics. In: Miller RD, editor. Miller's Anesthesia. 6th ed. Philadelphia: Elsevier, Inc.; 2005. pp. 573-603.

8. McLure HA, Rubin AP. Review of local anaesthetic agents. Minerva Anestesiol 2005;71:59-74.

9. Mulroy MF. Systemic toxicity and cardiotoxicity from local anesthetics: incidence and preventive measures. Reg Anesth Pain Med 2002;27:556-561.

10. Weinberg G. Lipid rescue resuscitation from local anaesthetic cardiac toxicity. Toxicol Rev 2006;25(3):139-145.

11. Beilin Y, Bodian CA, Haddad EM, Leibowitz AB. Practice patterns of anesthesiologists regarding situations in obstetric anesthesia where clinical management is controversial. Anesth Analg 1996;83:735-741.

12. Lidocaine hydrochloride. In: McEvoy GK, editor. AHFS drug information 2007. Bethesda, MD: American Society of Health-System Pharmacists, Inc.; 2007. p. 1599-1602.

13. Mather LE, Copeland SE, Ladd LA. Acute toxicity of local anesthetics: underlying pharmacokinetic and pharmacodynamic concepts. Reg Anesth Pain Med 2005;30:553-566.

14. Weinberg GL, Massad MG. Metabolic modulation for cardiac protection. Expert Rev Cardiovasc Ther 2007;5(2):135-138.

15. Intralipid ${ }^{\circledR} 20 \%$ (a 20\% I.V. fat emulsion in Excel ${ }^{\circledR}$ container) [package insert]. Deerfield, IL: Baxter Healthcare Corporation; 2006.

16. Olivecrona G, Olivecrona T. Clearance of artificial triacylglycerol particles. Curr Opin Clin Nutr Metab Care 1998; 1:143-151.
17. Weinberg GL, Ripper R, Murphy P, et al. Lipid infusion accelerates removal of bupivacaine and recovery from bupivacaine toxicity in the isolated rat heart. Reg Anesth Pain Med 2006;31:296-303.

18. Weinberg G, Ripper R, Feinstein DL, Hoffman W. Lipid emulsion infusion reduces dogs from bupivacaine-induced cardiac toxicity. Reg Anesth Pain Med 2003;28:198-202.

19. Huang JM, Xian H, Bacaner M. Long-chain fatty acids activate calcium channels in ventricular myocytes. Proc Natl Acad Sci USA 1992;89:6452-6456.

20. Ordway RW, Walsh JV, Singer JJ. Arachidonic acid and other fatty acids directly activate potassium channels in smooth muscle cells. Science 1989;244:1176-1179.

21. Weinberg GL, VadeBoncouer T, Ramaraju GA, GarciaAmaro MF, Cwik MJ. Pretreatment or resuscitation with a lipid infusion shifts the dose-response to bupivacaine-induced asystole in rats. Anesthesiology 1998;88(4):1071-1075.

22. Rosenblatt MA, Abel M, Fischer GW, Itzkovich CJ, Eisenkraft JB. Successful use of a $20 \%$ lipid emulsion to resuscitate a patient after a presumed bupivacaine-related cardiac arrest. Anesthesiology 2006;105:217-218.

23. Litz RJ, Popp M, Stehr SN, Koch T. Successful resuscitation of a patient with ropivacaine-induced asystole after axillary plexus block using lipid infusion. Anaesthesia 2006;61:800-801.

24. Foxall G, McCahon R, Lamb J, Hardman JG, Bedforth NM. Levobupivacaine-induced seizures and cardiovascular collapse treated with Intralipid ${ }^{\circledR}$. Anaesthesia 2007;62:516-518.

25 . Spence AG. Lipid reversal of central nervous system symptoms of bupivacaine toxicity. Anesthesiology 2007;107:516-517.

26. LipidRescue ${ }^{\mathrm{TM}}$ resuscitation for cardiac toxicity: treatment regimens [webpage on the Internet]. Treatment regimens. Weinberg G [cited 29 Aug 2007]. Available from: http://www.lipidrescue.org

27. Bania TC, Chu J, Perez E, Su M, Hahn IH. Hemodynamic effects of intravenous fat emulsion in an animal model of severe verapamil toxicity resuscitated with atropine, calcium, and saline. Acad Emerg Med 2007;14:105-111.

28. Kasi VS, Estrada CA, Wiese W. Association of pancreatitis with administration of contrast medium and intravenous lipid emulsion in a patient with the acquired immunodeficiency syndrome. South Med J 2003;96:66-69.

29. Han J, Davis SS, Washington C. Physical properties and stability of two emulsion formulations of propofol. Int J Pharm 2001;215:207-220.

30. Weinberg G, Hertz P, Newman J. Lipid, not propofol, treats bupivacaine overdose. Anesth Analg 2004;99:1871-1882.

31. Shupak RC. Lipid emulsion for bupivacaine toxicity: too soon to celebrate? Anesthesiology 2007;106:634-635.

32. Sirianni AJ, Osterhoudt KC, Calello DP, Mueller AA, Waterhouse MR, Goodkin MB, et al. Use of lipid emulsion in the resuscitation of a patient with prolonged cardiovascular collapse after overdose of bupropion and lamotrigine. Ann Emerg Med 2008;51:412-415. 